\title{
Corrections
}

\section{Correction: Buran et al., Onset Coding Is Degraded in Auditory Nerve Fibers from Mutant Mice Lacking Synaptic Ribbons}

In the article "Onset Coding Is Degraded in Auditory Nerve Fibers from Mutant Mice Lacking Synaptic Ribbons” by Bradley N. Buran, Nicola Strenzke, Andreas Neef, Eckart D. Gundelfinger, Tobias Moser, and M. Charles Liberman, which appeared on pages 7587-7597 of the June 2, 2010 issue, the legend for Figure 1C failed to acknowledge that the electron micrograph it contains was originally published as a portion of Figure 10 in Liberman MC (July 1980) Morphological differences among radial afferent fibers in the cat cochlea: an electron-microscopic study of serial sections. Hearing Research 3:45-63. This oversight does not affect the interpretation of the results.

DOI: 10.1523/JNEUROSCI.0666-12.2012 